\title{
Micron-size metal-binding hydrogel particles improve germination and radicle elongation of Australian metallophyte grasses in mine waste rock and tailings
}

J. Guterres School of Agriculture and Food Sciences, The University of Queensland, Australia

L. Rossato School of Agriculture and Food Sciences, The University of Queensland, Australia

A. Pudmenzky School of Agriculture and Food Sciences, The University of Queensland, Australia

D. Doley School of Agriculture and Food Sciences, The University of Queensland, Australia

M. Whittaker Centre for Advanced Macromolecular Design, The University of New South Wales, Australia

S. Schmidt School of Agriculture and Food Sciences, The University of Queensland, Australia

\begin{abstract}
Metal contamination of landscapes as a result of mining and other industrial activities is a pervasive problem worldwide. Metal contaminated soils often lack effective vegetation cover and are prone to contaminant leaching and dispersion through erosion, leading to contamination of the general environment. Hydrogels and similar hydrophilic and negatively-charged compounds are well-established ameliorants for wastes and tailings, but their application is constrained by transport (bulk), attributes, and cost. In this paper we demonstrate that metal-binding hydrogel particle amendments could be used to ameliorate substrates prior to planting, in order to enhance seedling emergence. In this study, micron-size thiol functional cross-linked acrylamide polymer hydrogel particles (X3) were synthesised and tested in laboratory-scale experiments on extremely saline and metal contaminated mine waste rock and tailings to determine: (i) their capacity to increase substrate water holding capacity (WHC); (ii) their metal-binding efficiency and capacity to reduce metal availability to plants to below the phytotoxicity threshold; and (iii) their effect on the germination characteristics and early radicle development of two Australian metallophyte grasses, Astrebla lappacea and Austrostipa scabra, under limiting and non-limiting water conditions.
\end{abstract}

Addition of $X 3$ to waste rock (18.4\% dry weight) and tailings (3.2\% dry weight) increased the WHC of both substrates, by more than $536 \%$ and $174 \%$ respectively, over the tested $\mathrm{pH}$ range from 2.0 to 6.3 . X3 also significantly $(P<0.05)$ lowered soluble concentrations of $A l$ and $\mathrm{Cu}$ in leachate from amended waste rock, by up to 55 and 59\% respectively between $\mathrm{pH} 3.2$ and 6.3. Below pH 3.2, metal-binding efficiency declined to almost zero, suggesting a loss of particle functionality in extremely acidic conditions.

$X 3$ was not toxic to seed germination and significantly $(P<0.05)$ increased germination percentages of A. lappacea and A. scabra in both waste rock and mine tailings in Petri dishes under controlled conditions. The highest germination percentages were recorded under a restricted water regime (substrates were watered to field capacity on the first day of the experiment but received no additional water thereafter). In A. lappacea, germination percentages increased to 43 and $10 \%$ in amended waste rock and tailings respectively compared to 9 and $0 \%$ in unamended treatments. In A. scabra, germination percentages increased from 0.5 to 24\%, and from 6 to 21\% in waste rock and tailings respectively. X3 also significantly $(P<0.05)$ enhanced the radicle elongation of both species in contaminated waste rock and tailings. Under restricted water regime, radicle length of $A$. lappacea was increased to up to 19 and $13.5 \mathrm{~mm}$ in amended waste rock and tailings respectively as compared with 2 and $3 \mathrm{~mm}$ in unamended treatments. In A. scabra, radicle length was increased to up to 5.5 and $4.5 \mathrm{~mm}$ in amended waste rock and tailings respectively versus 0 and $1 \mathrm{~mm}$ in unamended treatments. 
Overall, greater radicle growth in X3 amended waste rock and tailings in water limited environments suggests that $X 3$ was able to ameliorate metal toxicity to radicles, and provide moisture in water restricted conditions, which improved the imbibition and consequent germination of the seeds. X 3 appears to have potential for the establishment of vegetation on contaminated land and wastes through a combination of reduced metal toxicity and increased soil-water availability. Together, these factors can potentially stabilise surfaces and reduce leaching or runoff of contaminants.

\section{Introduction}

Heavy metal contaminated soils resulting from mining and other industrial activities are major environmental problems because they create unfavourable conditions for plant growth due to the lack of soil structure, low nutrient content, high salinity, high or low soil pH and elevated concentrations of toxic elements such as aluminium (Al), copper ( $\mathrm{Cu})$, lead $(\mathrm{Pb})$, nickel $(\mathrm{Ni})$, zinc $(\mathrm{Zn})$ and arsenic (As) (de Varennes et al., 2011). As a consequence, contaminated soils, tailings and waste rock may lack protective layers of vegetation that prevent dispersion of toxic contaminants to adjacent aquifers and other areas (Alvarez et al., 2003; Antonijevic et al., 2012; Mendez and Maier, 2008). The contaminants may be leached, absorbed by vegetation or retained by the soil (Alvarez et al., 2003) so they may enter the food chain and put human and wildlife health at risk.

A vegetative cover on mine wastes reduces dispersion of toxic elements to surrounding ecosystems (de Varennes et al., 2011). Phytoremediation is the use of metal tolerant plants (i.e. metallophytes) to remove or stabilise toxic elements in soils and is a cost-effective and ecologically advantageous approach compared to other remediation techniques such as excavation and disposal to landfill (Hegazy et al., 2011; Nedunuri et al., 2010; Salt et al., 1995). Native plant species are often preferred for phytoremediation as they are likely to be resilient to local stresses such as low soil nutrient and organic matter contents and climate (for instance drought in arid and semi arid environments) (Mendez and Maier, 2008). Moreover, they are generally not invasive, and thereby maintain and possibly increase local plant biodiversity (Keeling and Werren, 2005; Mendez and Maier, 2008). Grasses can often achieve rapid ground cover and limit short term erosion (Williams and Currey, 2002) and shrubs and trees offer a broad canopy cover and establish deep root systems that prevent erosion over the long term (Belsky et al., 1989; Tiedemann and Klemmedson, 2004). However, successful plant establishment of even metallophytes may be limited or impossible when metal contaminations in soils exceed plant toxicity thresholds. So, enhancing the quality of heavily impacted soils prior to revegetation is often a prerequisite for effective phytoremediation.

Nanotechnology offers a further approach to in situ remediation of metal contaminated soils which could complement existing techniques (Sun et al., 2006). The use of nanoparticles (surface-functionalised polymer and nanoscale zero-valent iron) to remove metals such as mercury $(\mathrm{Hg}), \mathrm{Pb}$, cadmium ( $\mathrm{Cd}$ ) and chromium ( $\mathrm{Cr}$ ) from contaminated water and soils has been reported previously (Bell et al., 2006; Singh et al., 2012). Plant establishment in polluted sites could be enhanced through the targeted design and application of micron- or nano-sized particles that have the capacity to bind toxic soluble metals in soils and improve plant-water relations (Rossato et al., 2011). For example, application of insoluble hydrophilic polyacrylate polymers in mine soil contaminated with $\mathrm{Pb}^{2+}$ has been shown to increase soil water holding capacity (Guiwei et al., 2008), reduce bioavailability of toxic trace elements such as $\mathrm{Pb}^{2+}$ and $\mathrm{Cu}^{2+}$, and enhanced plant growth (de Varennes and Queda, 2005; Guiwei et al., 2008; Torres and de Varennes, 1998). Application of hydrophilic polymers from diapers at $0.3 \%(\mathrm{~m} / \mathrm{m})$ to mine soil has also been found to induce faster establishment of plant cover ( $Q u$ and de Varennes, 2010). Nano-sized vivianite was effective in reducing the leachability and bioaccessibility of $\mathrm{Cu}(\mathrm{II})$ in calcareous, neutral and acidic soils (USEPA, 2005). Rossato et al. (2011) showed that micron-size thiol functional cross-linked acrylamide polymer particles (called X3) were able to reduce the available solution concentrations of $\mathrm{Pb}^{2+}(9.65 \mathrm{mM}), \mathrm{Cu}^{2+}(4 \mathrm{mM})$ and $\mathrm{Zn}^{2+}(10 \mathrm{mM})$ by $86.5,75.5$ and $63.84 \%$, respectively. They also reported that $\mathrm{X} 3$ was not toxic to seed germination as it allowed normal germination and root elongation of the native metallophyte curly Mitchell grass (Astrebla lappacea) at phytotoxic available concentrations of $\mathrm{Pb}^{2+}(9.65 \mathrm{mM})$ and $\mathrm{Zn}^{2+}(10 \mathrm{mM})$. 
The objectives of this study were i) to assess the potential of $X 3$ to bind toxic soluble metals in extremely saline and metal contaminated mine waste rock and tailings, and to increase substrate WHC, and ii) to investigate $\mathrm{X} 3$ effect on the germination characteristics and early radicle development of two Australian metallophyte grasses, Astrebla lappacea and Austrostipa scabra, under water limiting and non-limiting conditions.

\section{$2 \quad$ Materials and methods}

\subsection{Substrate collection and characterisation}

Substrates were collected from two mine sites where revegetation attempts had been unsuccessful for over 30 years. Waste rock (top $10 \mathrm{~cm}$ only) was collected from an abandoned gold mine in Queensland. Tailings (representative sample from the top $7 \mathrm{~m}$ ) was collected from an active base metal mine in Queensland, Australia. River sand with no metal contamination was used as a control and was collected from Mt. Tamborine (Australia) and acid washed and thoroughly rinsed with deionised water (DIW) prior to experiments.

All substrates were air dried, crushed, mixed and sieved $(<2 \mathrm{~mm})$ to produce a fine, homogenous medium. Substrates were then analysed for $\mathrm{pH}$ and $\mathrm{EC}$ in a soil water suspension (4 $\mathrm{g}$ of soil to $20 \mathrm{ml}$ distilled water) after shaking for $1 \mathrm{~h}$ by inversion at $\sim 40 \mathrm{rpm}$ in a Heidolph ReAx shaker and standing for $1 \mathrm{~h}$ (Rayment and Higginson, 1992). Plant available metals were extracted using $0.01 \mathrm{M} \mathrm{CaCl}_{2}(4 \mathrm{~g}$ of soil to $40 \mathrm{~mL} 0.01 \mathrm{M}$ $\mathrm{CaCl}_{2}$ ) (Menzies et al., 2007). Determination of total metals was achieved by reducing the substrate to fine particles using a ball mill (Planetary Ball Mills PM 200, RETSCH, Germany). Acids ( $5 \mathrm{~mL}$ nitric acid $70 \%$ from Labscan Asia Co. Ltd., Bangkok, $2 \mathrm{ml}$ hydrochloric acid $32 \%$ and $2.5 \mathrm{~mL}$ hydrofluoric acid $50 \%$ from Ajax Finechem, Australia) were added to 150-200 mg of sample which was then heated in a microwave digester (MDS-200, CEM Corporation) at $120 \mathrm{~atm}(12.16 \mathrm{MPa})$ and $185^{\circ} \mathrm{C}$ for 30 minutes. Samples were then analysed for a range of metals using inductively coupled plasma optical emission spectroscopy (ICP-OES) or inductively coupled plasma mass spectrometry (ICP-MS). A National Institute Standard and Technology (NIST) Standard Reference Material (SRM) (2709 San Joaquin soil) which has certified values for most of the metals was used to verify the measurements.

\subsection{Determination of metal-binding and water holding capacities of $\mathrm{X} 3$ in mine substrates under various $\mathrm{pH}$ conditions}

Mixing experiments were carried out to test the efficiency of functional $\mathrm{X} 3$ in reducing available concentrations of metals and increasing the $\mathrm{WHC}$ of the waste rock and tailings over a large $\mathrm{pH}$ range $(6.3$ to 2) in DIW and $0.01 \mathrm{M} \mathrm{CaCl}_{2}$. Two different percentages of $\mathrm{X} 3$ were added to each substrate based on their plant available metal contents so as to bind all or half of the soluble metals as described by Rossato et al. (2011). For DIW treatments (pH 6.3), percentages of $X 3$ added to substrates were 18.4 and $9.2 \%$ dry weight (DW) for waste rock and 3.2 and $1.6 \%$ DW for tailings. For $0.01 \mathrm{M} \mathrm{CaCl}_{2}$ treatments (pH 6.3 to 2), $9.2 \% \mathrm{DW}$ and $1.6 \% \mathrm{DW}$ of $\mathrm{X} 3$ were added to waste rock and tailings respectively. Required amounts of $\mathrm{X} 3$ were thoroughly mixed with substrates for $12 \mathrm{~h}$ using a shaker (Gerhardt Rotoshake RS12 Elution Shaker) at $5 \mathrm{rpm}$.

Ten $\mathrm{mL}$ of DIW (pH 6.3) or $0.01 \mathrm{M} \mathrm{CaCl}_{2}$ at various $\mathrm{pH}$ were added to one gram of waste rock or tailings unamended or amended with $\mathrm{X} 3$ in $50 \mathrm{~mL}$ polypropylene conical tubes. Samples were shaken overnight $(12 \mathrm{~h})$ at $5 \mathrm{rpm}$ and then centrifuged $\left(3,000 \mathrm{rpm}\right.$ for $30 \mathrm{~min}$ at $22^{\circ} \mathrm{C}$ ). The supernatant (mine substrate leachate), which contained the fraction of free soluble metals not bound to the particles, was pipetted into $10 \mathrm{~mL}$ PPTR tubes and $25 \mu \mathrm{L}$ of nitric acid (70\%) was added per $1 \mathrm{~mL}$ of supernatant with stirring to digest the samples prior to metal analysis via ICP-OES/MS. Three replicates per treatment were used.

The metal-binding efficiencies of the particles in mine substrates were calculated using the formula by Rossato et al. (2011): 
The water holding capacities (WHC) of waste rock and tailings under saturated conditions were calculated using the formula below (Rossato et al., 2011):

$$
\mathrm{WHC}(\% \mathrm{DW})=\frac{\mathrm{w}_{\mathrm{h}-} \mathrm{w}_{\mathrm{d}}}{\mathrm{w}_{\mathrm{d}}} \times 100
$$

Where:

$\mathrm{W}_{\mathrm{h}} \quad=\quad$ hydrated weight of unamended or $\mathrm{X} 3$ amended waste rock or tailings.
$\mathrm{W}_{\mathrm{d}} \quad=\quad$ dry weight of unamended or $\mathrm{X} 3$ amended waste rock or tailings.

\subsection{Measurement of germination characteristics and radicle elongation of A. lappacea and $A$. scabra in mine substrates amended with $\mathrm{X} 3$ under different water regimes}

Viable seeds of $A$. lappacea and A. scabra were obtained from Native Seeds (New South Wales, Australia). They were not dormant as the seeds had been collected and stored dry at $3-5^{\circ} \mathrm{C}$ for more than 12 months prior to the germination experiments.

The amounts of X3 particles applied to waste rock and tailings were calculated so as to bind all toxic soluble metal as described by Rossato et al. (2011) and were 18.4 and 3.2\% DW for waste rock and tailings respectively. Particles were mixed with the waste rock and tailings overnight using a shaker (Gerhardt Rotoshake RS12 Elution Shaker) at $5 \mathrm{rpm}$. Uncontaminated acid washed river sand was used for the control.

Seeds were surface-sterilised in $20 \%$ sodium hypochlorite for $10 \mathrm{~min}$ and then rinsed three times in sterilised deionised water (SDIW) for one min. Thirteen grams of waste rock or tailings or $20 \mathrm{~g}$ of sand (control) with or without particles were placed in each Petri dish (disposable dish $90 \times 25 \mathrm{~mm}$ ) and a predetermined volume of SDIW was added to each dish to bring it to field capacity. Forty seeds of each species were placed on top of the substrates in each Petri dish, with five replicates for each treatment. Two different water regimes (field capacity and water-limited) were tested to investigate the potential of the X3 particles to supply water during a normal germination period.

The Petri dish treatments maintained at field capacity were sealed with parafilm and placed in a transparent plastic zip resealable bag to minimise water loss. In the water-limited treatments, substrates were watered to field capacity on the first day of the experiment but received no additional water thereafter. Water-limited Petri dishes were not sealed with parafilm nor placed in plastic bags. All the Petri dishes were placed in a germination cabinet under controlled conditions $\left(30^{\circ} \mathrm{C}\right.$ day, $25^{\circ} \mathrm{C}$ night, 12 hours light per day).

Germinated seeds were counted and removed daily, within a laminar flow cabinet until the maximum germination percentage was reached i.e. for 15 and 21 days for A. scabra and A. lappacea respectively. Seeds were considered germinated when $1 \mathrm{~mm}$ of radicle had emerged.

Mean germination times (MGT) were calculated using the following formula of Ellis and Roberts (1981):

$$
M G T=\frac{\sum D n}{\sum n}
$$

Where:

$D=$ number of days counted since the beginning of the experiment.

$n=$ number of germinated seeds on day $\mathrm{D}$. 
Radicle length of germinated seeds was measured from the radicle-shoot junction to the tip of the longest radicles after three days for $A$. scabra and four days for $A$. lappacea.

The radicle tolerance index (RTI) was used as sensitive indicator of the alleviation of the substrate toxicity by X3 addition (Rossato et al., 2011) and was calculated using the following formula (Ellis and Roberts, 1981):

$$
\mathrm{RTI}=\frac{\text { Length } \text { of the longest radicle in } \mathrm{X} 3 \text { amended substrate }}{\text { Length of the longest radicle in control substrate }} \times 100
$$

Where:

Control substrate $\quad=\quad$ sand treatment alone or with $\mathrm{X} 3$ particles as appropriate.

\subsection{Determination of $\mathrm{pH}$, plant available metal concentrations and cumulative evaporation in germination substrates}

Substrates used for germination experiments were collected and air dried at the end of the experiment for $\mathrm{pH}$ and plant available metal analysis following the methods described in the Section 2.1.

Cumulative evaporation in germination substrates was measured by weighing germination Petri dishes on every second day until Day 14 for A. scabra and Day 20 for A. lappacea. For field capacity treatment, weighing of the Petri dishes was done before addition of SDIW.

\section{Data analysis}

Data were presented as means and standard errors of either three (mixing experiment) or five (germination experiment) replicates, and they were tested for significant differences between treatment means using Student's t-tests in Microsoft Office Excel 2007. Analyses were conducted using a 95\% confidence interval and statistical significance was indicated by $\mathrm{P}$-values $\mathrm{P}<0.05$.

\section{$4 \quad$ Results}

\subsection{Characteristics of substrates}

Characterisations of the waste rock and tailings are presented in Table 1. Aluminium and copper were the major contaminants of waste rock and total concentrations of these metals $(A)=29,000 \mathrm{mg} \mathrm{kg}^{-1}$ and $\mathrm{Cu}=1,289 \mathrm{mg} \mathrm{kg}^{-1}$ ) reached recognised soil plant toxicity levels (Kopittke et al., 2010; Mendez and Maier, 2008). The plant available concentrations of $\mathrm{Al}\left(308 \mathrm{mg} \mathrm{kg}^{-1}\right)$ and $\mathrm{Cu}\left(34.6 \mathrm{mg} \mathrm{kg}^{-1}\right)$ were also high compared to toxicity threshold limits for plants of $0.5 \mathrm{mg} \mathrm{kg}^{-1}$ of Al or Cu (Mulvey and Elliott, 2000). Other metals, manganese $(\mathrm{Mn})$ and $\mathrm{Zn}$ were also present in the waste rock although their plant available concentrations were lower than plant toxicity levels for these metals. Concentrations of total sodium ( $\mathrm{Na}$ ) and sulphur (S) in waste rock exceeded plant toxicity limits (Mulvey and Elliott, 2000). Unlike waste rock, the main contaminants in tailings were $\mathrm{Mn}$ and $\mathrm{Zn}$ with total and plant available concentrations of these metals exceeding plant toxicity limits (Kopittke et al., 2010; Mendez and Maier, 2008). Total Al and Cu were also high but the bioavailabilities of these metals were lower than the plant toxicity levels. The tailings also contained total $\mathrm{Na}$ and S with concentrations above toxicity limits for plants (Mulvey and Elliott, 2000). Sand showed no trace of metal contamination (Table 1) and was an appropriate control for the germination experiment.

The waste rock was also very acidic $(\mathrm{pH} 3.03 \pm 0.003)$. With very low $\mathrm{pH}$, the plant availabilities of metals in waste rock, such as $\mathrm{Al}, \mathrm{Cu}$ and $\mathrm{Zn}$ are likely to increase as these metals are more available at low $\mathrm{pH}$. In contrast, $\mathrm{pH}$ of the tailings was neutral $(7.09 \pm 0.006)$ which would reduce metal availability to plants. Both substrates were extremely saline $\left(E C=2.79 \pm 0.003\right.$ and $3.63 \pm 0.006 \mathrm{mS} . \mathrm{cm}^{-1}$ in waste rock and tailings, respectively; The State of Queensland, 2011). These ECs are toxic to plants, reducing growth, early maturation and plant yield (50\% yield reduction was observed in grasses) (Mulvey and Elliott, 2000). 
Table 1 Characterisation of waste rock, tailings and sand (control). Results are given as the mean \pm standard error $(S E)(n=3)$

\begin{tabular}{|c|c|c|c|c|c|c|}
\hline \multirow[t]{2}{*}{ Elements } & \multicolumn{2}{|c|}{ Waste Rock } & \multicolumn{2}{|c|}{ Tailings } & \multicolumn{2}{|c|}{ Sand (Control) } \\
\hline & $\left(\mathrm{mg} \mathrm{kg}^{-1}\right)$ & $\begin{array}{c}\text { Plant } \\
\text { Available } \\
\left(0.01 \mathrm{M} \mathrm{CaCl}_{2}\right) \\
\left(\mathrm{mg} \mathrm{kg}^{-1}\right)\end{array}$ & $\left(\mathrm{mg} \mathrm{kg}^{-1}\right)$ & $\begin{array}{c}\text { Plant } \\
\text { Available } \\
\left(0.01 \mathrm{M} \mathrm{CaCl}_{2}\right) \\
\left(\mathrm{mg} \mathrm{kg}^{-1}\right)\end{array}$ & $\left(\mathrm{mg} \mathrm{kg}^{-1}\right)$ & $\begin{array}{c}\text { Plant } \\
\text { Available } \\
\left(0.01 \mathrm{M} \mathrm{CaCl}_{2}\right) \\
\left(\mathrm{mg} \mathrm{kg}^{-1}\right)\end{array}$ \\
\hline Al & $29,000 \pm 703$ & $308 \pm 4.5$ & $14,566 \pm 388$ & $0.9 \pm 0.4$ & $15,049 \pm 294$ & $0.0 \pm 0.0$ \\
\hline $\mathrm{Cu}$ & $1,389 \pm 11$ & $34.6 \pm 0.6$ & $842 \pm 16$ & $0.2 \pm 0.0$ & $0.0 \pm 0.0$ & $0.0 \pm 0.0$ \\
\hline $\mathrm{Na}$ & $8,279 \pm 109$ & - & $602 \pm 25$ & - & $4,051 \pm 97$ & - \\
\hline$S$ & $23,856 \pm 454$ & - & $44,070 \pm 792$ & - & $193 \pm 14$ & - \\
\hline $\mathrm{Mn}$ & $452 \pm 52$ & $8.0 \pm 0.2$ & $2,706 \pm 51$ & $76.7 \pm 1.7$ & $166 \pm 1.6$ & $0.2 \pm 0.0$ \\
\hline $\mathrm{Zn}$ & $368 \pm 6.4$ & $4.6 \pm 0.1$ & $3,647 \pm 75$ & $18.5 \pm 0.4$ & $8 \pm 0.7$ & $0.0 \pm 0.0$ \\
\hline
\end{tabular}

\subsection{Effect of $\mathrm{X} 3$ particles on soluble metal concentrations in mine waste leachates}

X3 particles significantly reduced soluble concentrations of $\mathrm{Al}$ and $\mathrm{Cu}$ in leachate of amended waste rock (Table 2). Concentrations of soluble metals in waste rock amended with $9.2 \%$ DW of X3 were decreased by about 23\% for Al (from 26.5 to $20.3 \mathrm{mg} \mathrm{L}^{-1}$ ) and $27 \%$ for $\mathrm{Cu}$ (from 3.6 to $2.7 \mathrm{mg} \mathrm{L}^{-1}$ ) compared to unamended waste rock. The concentrations of $\mathrm{Al}$ and $\mathrm{Cu}$ in amended waste rock were further reduced by $40 \%$ (to $12 \mathrm{mg} \mathrm{L}^{-1}$ ) and $43 \%$ (to $1.5 \mathrm{mg} \mathrm{L}^{-1}$ ) respectively when the percentages of $\mathrm{X} 3$ was increased to $18.4 \%$.

The $\mathrm{pH}$ did not affect the functionality of $\mathrm{X} 3$ in reducing soluble concentrations of $\mathrm{Al}$ and $\mathrm{Cu}$ in leachate of $\mathrm{X} 3$-amended waste rock (9.2\% DW) between pH 6.3 and 3.2 (Table 2). The average reduction of Al and $\mathrm{Cu}$ soluble concentrations was almost constant at $23.5 \pm 1.5 \%$ and $26.7 \pm 1.6 \%$ between pH 6.3 and 3.2. Below $\mathrm{pH} 3.2$, percentage metal reduction decreased to $5.6 \pm 1.0 \%$ for $\mathrm{Al}$ and $0 \%$ for $\mathrm{Cu}$, which suggests a loss of particle functionality in extremely acidic conditions.

Table 2 Soluble concentrations of metals in leachate of waste rock at different percentages of $\mathrm{X} 3$ and under various $\mathrm{pH}$ conditions in DIW and $0.01 \mathrm{M} \mathrm{CaCl}_{2}$. Data are presented as the mean \pm SE $(n=3)$; nt stands for 'not tested'

\begin{tabular}{|c|c|c|c|c|c|c|c|}
\hline \multirow{4}{*}{ Extractant } & \multirow[b]{4}{*}{$\mathrm{pH}$} & \multicolumn{6}{|c|}{ Solution Metal Concentration $\left(\mathrm{mg} \mathrm{L}^{-1}\right)$ in Waste Rock Leachates } \\
\hline & & \multirow{2}{*}{\multicolumn{3}{|c|}{$\begin{array}{l}\text { Al } \\
\text { Percentage of X3 to Waste Rock } \\
\text { (\% DW) }\end{array}$}} & \multirow{2}{*}{\multicolumn{3}{|c|}{$\begin{array}{l}\mathrm{Cu} \\
\text { Percentage of X3 to Waste Rock } \\
(\% \mathrm{DW})\end{array}$}} \\
\hline & & & & & & & \\
\hline & & 0 & 9.2 & 18.4 & 0 & 9.2 & 18.4 \\
\hline DIW & 6.3 & $26.5 \pm 0$ & $20.3 \pm 0.6$ & $12 \pm 0.1$ & $3.6 \pm 0$ & $2.7 \pm 0.1$ & $1.5 \pm 0$ \\
\hline $0.01 \mathrm{M} \mathrm{CaCl}_{2}$ & 6.3 & $31 \pm 0.3$ & $21.6 \pm 2$ & nt & $3.7 \pm 0$ & $2.4 \pm 0.2$ & nt \\
\hline $0.01 \mathrm{M} \mathrm{CaCl}_{2}$ & 5.2 & $30.4 \pm 0.8$ & $23.5 \pm 0.1$ & nt & $3.6 \pm 0.1$ & $2.7 \pm 0$ & nt \\
\hline $0.01 \mathrm{M} \mathrm{CaCl}_{2}$ & 4.5 & $31.2 \pm 0.2$ & $23.6 \pm 0.8$ & nt & $3.7 \pm 0$ & $2.7 \pm 0.1$ & nt \\
\hline $0.01 \mathrm{M} \mathrm{CaCl}_{2}$ & 3.2 & $33.3 \pm 0.7$ & $25.9 \pm 0.3$ & nt & $4 \pm 0.1$ & $3 \pm 0$ & nt \\
\hline $0.01 \mathrm{M} \mathrm{CaCl}_{2}$ & 2 & $47 \pm 0.8$ & $45.3 \pm 0.3$ & nt & $5 \pm 0.1$ & $5.1 \pm 0$ & nt \\
\hline
\end{tabular}

As compared with waste rock, tailings had relatively low soluble metal concentrations in leachates and addition of $X 3$ did not significantly ( $P>0.05$ ) decrease concentrations of soluble metals (data not shown). 


\subsection{Water holding capacities of mine substrates amended with X3}

The WHCs of unamended and X3 amended waste rock and tailings were tested to examine the potential of $\mathrm{X} 3$ to provide water for imbibition and germination of seeds. X3 particles greatly improved WHCs of both the waste rock (at 9.2 and $18.4 \%$ DW of $X 3$ ) and tailings (at 1.6 and $3.2 \%$ DW of X3) (Table 3). The addition of $9.2 \%$ of $X 3$ to waste rock and $1.6 \%$ of $X 3$ to tailings increased the WHCs of the substrates approximately 4.5 fold (42 to $190 \%$ ) and 2 fold ( 29 to $60 \%$ ) respectively. As the percentages of $X 3$ increased to $18.4 \%$ for waste rock and $3.2 \%$ for tailings, the WHCs of the substrates increased significantly, to around 266 and $79 \%$, respectively.

There was no effect of $\mathrm{pH}$ on the capacity of $\mathrm{X} 3$ particles to increase the WHCs of waste rock and tailings (Table 3). Compared with unamended waste rock and tailings, the WHCs of X3-amended waste rock (9.2\% DW of X3) and tailings (1.6\% DW of X3) in $0.01 \mathrm{M} \mathrm{CaCl}_{2}$ solution increased by nearly five times from 44 to $210 \%$ and by two times from 29 to $59 \%$, respectively and were constant over the range of pH tested (6.3 to 2 ).

\section{Table 3 Water holding capacities of waste rock and tailings amended with different percentages of $\mathrm{X} 3$ and under various $\mathrm{pH}$ conditions in $\mathrm{DIW}$ and $0.01 \mathrm{M} \mathrm{CaCl}_{2}$. Data are presented as the mean \pm SE $(n=3)$; $n t$ stands for 'not tested'}

\begin{tabular}{cccccc}
\hline & & \multicolumn{4}{c}{$\begin{array}{c}\text { Substrate Water Holding Capacities (\% DW) } \\
\text { Percentage of X3 to Substrates (\% DW) }\end{array}$} \\
Treatment & Extractant & $\mathbf{p H}$ & $\mathbf{0 \%}$ & $\mathbf{9 . 2 \%}$ & $\mathbf{1 8 . 4 \%}$ \\
\hline Waste rock & $\mathrm{DIW}$ & 6.3 & $42.2 \pm 0.3$ & $189.8 \pm 11$ & $265.8 \pm 4.9$ \\
& $0.01 \mathrm{M} \mathrm{CaCl}_{2}$ & 6.3 & $36.3 \pm 1.3$ & $211.9 \pm 18.9$ & $\mathrm{nt}$ \\
& $0.01 \mathrm{M} \mathrm{CaCl}_{2}$ & 5.2 & $43.4 \pm 3.7$ & $201.9 \pm 14.1$ & $\mathrm{nt}$ \\
& $0.01 \mathrm{M} \mathrm{CaCl}_{2}$ & 4.5 & $47.4 \pm 1$ & $199.3 \pm 13.6$ & $\mathrm{nt}$ \\
& $0.01 \mathrm{M} \mathrm{CaCl}_{2}$ & 3.2 & $47.1 \pm 1$ & $187.7 \pm 5.6$ & $\mathrm{nt}$ \\
& $0.01 \mathrm{M} \mathrm{CaCl}_{2}$ & 2 & $43.7 \pm 2.1$ & $243.0 \pm 26.7$ & $\mathrm{nt}$ \\
& & & $\mathbf{0 \%}$ & $\mathbf{1 . 6 \%}$ & $\mathbf{3 . 2 \%}$ \\
& $\mathrm{DIW}_{\text {Tailings }}$ & 6.3 & $28.8 \pm 0.3$ & $59.6 \pm 5.3$ & $\mathbf{7 8 . 8} \pm 4.4$ \\
& $0.01 \mathrm{M} \mathrm{CaCl}_{2}$ & 6.3 & $28.5 \pm 1.2$ & $58.3 \pm 1.3$ & $\mathrm{nt}$ \\
& $0.01 \mathrm{M} \mathrm{CaCl}_{2}$ & 5.2 & $33.0 \pm 1.7$ & $62.2 \pm 1.7$ & $\mathrm{nt}$ \\
& $0.01 \mathrm{M} \mathrm{CaCl}_{2}$ & 4.5 & $29.6 \pm 1.1$ & $59.7 \pm 1.4$ & $\mathrm{nt}$ \\
& $0.01 \mathrm{M} \mathrm{CaCl}_{2}$ & 3.2 & $27.6 \pm 0.8$ & $59.4 \pm 0.2$ & $\mathrm{nt}$ \\
& $0.01 \mathrm{M} \mathrm{CaCl}_{2}$ & 2 & $27.8 \pm 0.4$ & $57.0 \pm 3.1$ & $\mathrm{nt}$ \\
\hline
\end{tabular}

\subsection{Effect of $\mathrm{X} 3$ on seed germination}

\subsubsection{Effect of $\mathrm{X} 3$ on $\mathrm{pH}$, plant available metal concentrations and cumulative evaporation of germination substrates}

Waste rock used for the germination experiment was analysed for $\mathrm{pH}$ and plant available metal concentrations after the experiment concluded (Table 4Table ). Regardless of the water treatment and the grass species, the addition of $X 3$ increased the $\mathrm{pH}$ significantly $(\mathrm{P}<0.05)$, from around 3.2 to up to 3.9.

Plant available concentrations of $\mathrm{Al}$ and $\mathrm{Cu}$ in waste rock decreased remarkably and significantly $(\mathrm{P}<0.05)$ with the addition of $\mathrm{X} 3$ in the substrates of both grass species (Table 4). Metal concentrations were lowered by between 78 and $85 \%$ and between 70 and $81 \%$ for water limited and field capacity treatments respectively, and maintained below the phytotoxicity thresholds for Astrebla lappacea and Austrostipa scabra. 
Table $4 \mathrm{pH}$ and plant available metal concentrations $\left(0.01 \mathrm{M} \mathrm{CaCl}_{2}\right)$ in unamended and X3 amended (18.4\% DW) waste rock used for the germination of $A$. lappacea and $A$. scabra under two different water regimes. Data are presented as the mean $\pm \operatorname{SE}(n=3)$

\begin{tabular}{lccc}
\hline & \multicolumn{3}{c}{$\begin{array}{c}\text { Plant Available Metal } \\
\text { Concentration }\left(\mathbf{m g ~ k g}^{-1}\right)\end{array}$} \\
Treatment & pH & Al & Cu \\
\hline a) A. lappacea & & & \\
Waste rock + water limited & $3.3 \pm 0$ & $239 \pm 1$ & $27.6 \pm 0.2$ \\
Waste rock + field capacity & $3.3 \pm 0$ & $212.6 \pm 3.4$ & $23.1 \pm 0.4$ \\
Waste rock + X3 + water limited & $3.9 \pm 0$ & $38.2 \pm 0.8$ & $6.0 \pm 0.3$ \\
Waste rock + X3 + field capacity & $3.8 \pm 0$ & $46.3 \pm 1$ & $6.8 \pm 0.2$ \\
b) A. scabra & & & \\
Waste rock + water limited & $3.3 \pm 0$ & $281.2 \pm 2.3$ & $31.8 \pm 0.2$ \\
Waste rock + field capacity & $3.2 \pm 0$ & $290 \pm 1.7$ & $32.2 \pm 0.3$ \\
Waste rock + X3 + water limited & $3.9 \pm 0$ & $42.6 \pm 2.1$ & $6.4 \pm 0.2$ \\
Waste rock + X3 + field capacity & $3.9 \pm 0$ & $54.0 \pm 1.6$ & $7.3 \pm 0.1$ \\
\hline
\end{tabular}

In tailings, regardless of the water treatment and the grass species, addition of $X 3(3.2 \% \mathrm{DW})$ did not modify $\mathrm{pH}$ and plant available metal concentrations, which were not significantly different $(p>0.05)$ from those in unamended tailings (Data not shown).

Cumulative evaporation from the substrates for both species was also measured during the germination experiment (Figure 1). Unamended waste rock and tailings maintained uniform evaporation for 10 days, by which time they appeared dry. For unamended sand (control), evaporation ceased after 14 days.

In the presence of $\mathrm{X} 3$, cumulative evaporation increased linearly for at least 20 days in waste rock and control sand (Figure 1a) and for 18 days in tailings under restricted water regime (Figure 1b) for A. lappacea. This shows that $\mathrm{X} 3$ increased the capacities of both substrates to hold water and release it progressively during the germination period under restricted water conditions. The cumulative water loss from the waste rock was greater than from the tailings as the percentage of X3 added to waste rock was 18.4\% DW against only 3.2\% DW for tailings (Figures $1 \mathrm{a}$ and $1 \mathrm{~b}$ ). In field capacity treatments, the evaporation rates were low in both substrates amended with $\mathrm{X} 3$ because the Petri dishes were placed in plastic zip resealable bags to reduce water loss (Figures $1 \mathrm{a}$ and $1 \mathrm{~b}$ ). Similar trends were observed for A. scabra (Figures 1c and 1d).

\subsubsection{Effect of X3 on germination percentages and mean germination time of A. lappacea and A. scabra in germination substrates}

The capacity of X3 particles to bind metals and provide water to plants in contaminated soils was tested in a germination experiment using Australian native metallophyte grasses, A. lappacea and A. scabra. X3 particles were not toxic to seed germination and significantly $(P<0.05)$ enhanced germination percentages of A. lappacea and A. scabra in both waste rock and mine tailings (Table 5). Increases in germination percentages under restricted water regime were significantly $(P<0.05)$ higher than in field capacity treatments except for $A$. lappacea on tailings. 


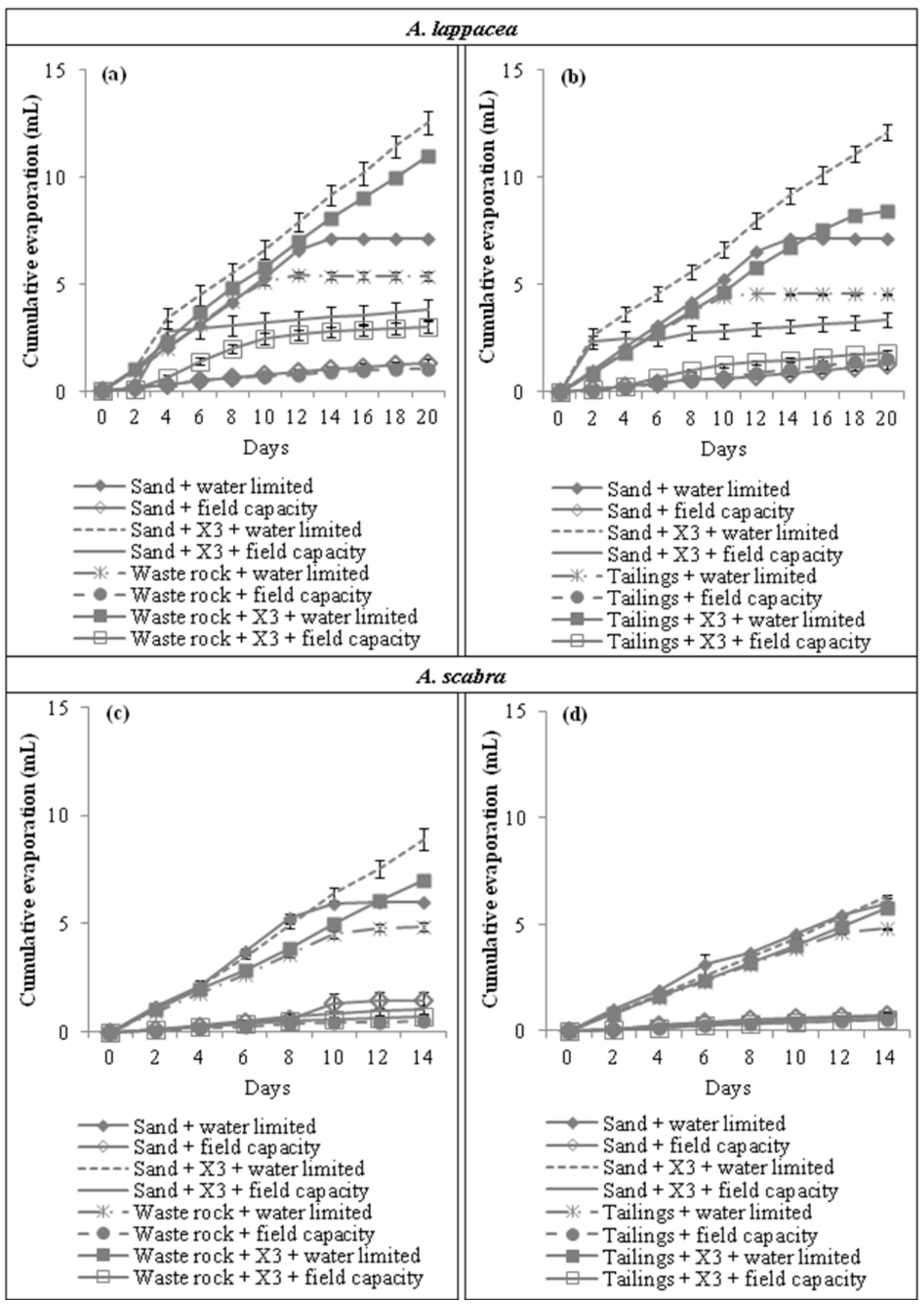

Figure 1 Cumulative water loss from sand, waste rock and tailings for A. lappacea (a and $b$ ) and $A$. scabra (c and d) in Petri dishes maintained at field capacity or water limited conditions. Vertical bars when larger than the symbol indicate \pm SE of the mean $(n=5)$ 
In A. lappacea, maximum germination percentages at field capacity increased significantly $(\mathrm{P}<0.05)$ with $\mathrm{X} 3$ amendment, from 0.5 to $29.6 \%$ and 12.9 to $23 \%$ for waste rock and tailings respectively. The increase was higher for waste rock under the water limited regime $(43.5 \%$ in $X 3$ amended compared to $9.4 \%$ in unamended waste rock). The maximum germination percentage of $A$. lappacea in tailings was about $10.4 \%$ in the water limited treatment versus only $0.9 \%$ in the unamended water limited control. In $A$. scabra, maximum germination percentages increased significantly $(\mathrm{P}<0.05)$ on $\mathrm{X} 3$ amended substrates (from 0 to $12 \%$ and 0.5 to $24.5 \%$ in waste rock; from 8 to $13.5 \%$ and 6.5 to $21.5 \%$ in tailings) under field capacity and water limited regimes respectively. Overall, maximum germination percentages of both species in X3 amended waste rock and tailings at field capacity were not significantly different $(P>0.05)$ from the relevant sand controls. Under water restricted conditions and with the exception of $A$. scabra in amended waste rock (significantly higher, $\mathrm{P}<0.05$ ) and in amended tailings (not significantly different, $\mathrm{P}>0.05$ ), maximum germination percentages were lower $(P<0.05)$ than the amended sand controls but significantly higher $(P<0.05)$ than the unamended waste controls.

Addition of $X 3$ particles to waste rock and tailings did not significantly ( $P>0.05)$ affect the MGT of either A. lappacea or A. scabra, with the exception of A. lappacea in tailings at field capacity, where germination was accelerated by almost five days in the presence of X3 (Table 5). MGTs of both grasses in both substrates was not affected by the addition of $X 3$ to limited water treatments and were not significantly different ( $p>0.05$ ) from those at field capacity, with the exception of $A$. lappacea, which germinated nearly 3.5 days faster in tailings under water limited conditions. Regardless of the water treatment, MGTs of both species in X3 amended mine substrates were not significantly different $(P>0.05)$ from the appropriate sand control, except for A. scabra in amended tailings under limited water regime which was slightly higher $(P<0.05)$ than the amended sand control.

Table 5 Maximum germination percentage (MaxGerm \%) and MGT of A. lappacea and A. scabra on unamended and X3 amended waste rock (18.4\% DW of X3) and tailings (3.2\% DW of $\mathrm{X} 3$ ) under different water regimes. Results are given as the mean $\pm S E(n=5)$. Treatments with the same letter do not differ significantly $(P>0.05)$; asterisks indicate values based on one replicate only

\begin{tabular}{lcccc}
\hline & \multicolumn{2}{c}{ A. Lappacea } & \multicolumn{2}{c}{ A. Scabra } \\
Treatment & MaxGerm (\%) & MGT (Days) & MaxGerm (\%) & MGT (Days) \\
\hline a) Waste rock & & & & \\
Sand + water limited & $20.5 \pm 2.9^{\mathrm{a}}$ & $5.3 \pm 0.3^{\mathrm{a}}$ & $15.5 \pm 3.0^{\mathrm{ac}}$ & $3.1 \pm 0.1^{\mathrm{a}}$ \\
Sand + field capacity & $29.7 \pm 6.5^{\mathrm{aef}}$ & $4.1 \pm 0.1^{\mathrm{b}}$ & $18 \pm 2.4^{\mathrm{ac}}$ & $3.0 \pm 0.2^{\mathrm{a}}$ \\
Sand + X3 + water limited & $78.4 \pm 3.9^{\mathrm{b}}$ & $5.4 \pm 0.3^{\mathrm{a}}$ & $14.0 \pm 3.0^{\mathrm{a}}$ & $5.2 \pm 0.8^{\mathrm{b}}$ \\
Sand + X3 + field capacity & $18.4 \pm 6.5^{\mathrm{acf}}$ & $4.5 \pm 1.1^{\mathrm{ab}}$ & $15.0 \pm 3.5^{\mathrm{ac}}$ & $3.1 \pm 0.4^{\mathrm{a}}$ \\
Waste rock + water limited & $9.4 \pm 3.2^{\mathrm{c}}$ & $4.6 \pm 0.3^{\mathrm{ab}}$ & $0.5 \pm 0.5^{\mathrm{b}}$ & $6^{*}$ \\
Waste rock + field capacity & $0.5 \pm 0.5^{\mathrm{d}}$ & $4^{*}$ & $0.0 \pm 0.0^{\mathrm{b}}$ & - \\
Waste rock + X3 + water limited & $43.5 \pm 4.0^{\mathrm{e}}$ & $4.7 \pm 0.4^{\mathrm{ab}}$ & $24.5 \pm 2.7^{\mathrm{c}}$ & $4.7 \pm 0.4^{\mathrm{b}}$ \\
Waste rock + X3 + field capacity & $29.6 \pm 3.0^{\mathrm{f}}$ & $5.2 \pm 0.3^{\mathrm{a}}$ & $12.0 \pm 2.0^{\mathrm{a}}$ & $3.9 \pm 0.7^{\mathrm{ab}}$ \\
b) Tailings & & & & \\
Sand + water limited & $20.5 \pm 2.9^{\mathrm{ade}}$ & $5.3 \pm 0.3^{\mathrm{a}}$ & $20.5 \pm 3.0^{\mathrm{ac}}$ & $2.7 \pm 0.1^{\mathrm{a}}$ \\
Sand + field capacity & $29.7 \pm 6.5^{\mathrm{a}}$ & $4.1 \pm 0.1^{\mathrm{b}}$ & $13.5 \pm 0.6^{\mathrm{bd}}$ & $2.9 \pm 0.2^{\mathrm{a}}$ \\
Sand + X3 + water limited & $80.1 \pm 2.9^{\mathrm{b}}$ & $4.1 \pm 0.1^{\mathrm{b}}$ & $22.0 \pm 2.3^{\mathrm{a}}$ & $5.1 \pm 0.6^{\mathrm{b}}$ \\
Sand + X3 + field capacity & $18.4 \pm 1.9^{\mathrm{ade}}$ & $5.3 \pm 0.7^{\mathrm{abd}}$ & $13.5 \pm 1.7^{\mathrm{cd}}$ & $2.5 \pm 0.2^{\mathrm{a}}$ \\
Tailings + water limited & $0.9 \pm 0.9^{\mathrm{c}}$ & $4^{*}$ & $6.5 \pm 1.3^{\mathrm{e}}$ & $4.4 \pm 0.4^{\mathrm{b}}$ \\
Tailings + field capacity & $12.9 \pm 2.4^{\mathrm{de}}$ & $11.5 \pm 1^{\mathrm{c}}$ & $8.0 \pm 1.5^{\mathrm{e}}$ & $7.5 \pm 1.8^{\mathrm{b}}$ \\
Tailings + X3 + water limited & $10.4 \pm 3.6^{\mathrm{e}}$ & $3.4 \pm 0.9^{\mathrm{ab}}$ & $21.5 \pm 4.9^{\mathrm{ad}}$ & $5.0 \pm 0.3^{\mathrm{b}}$ \\
Tailings + X3 + field capacity & $23 \pm 2.4^{\mathrm{a}}$ & $6.7 \pm 0.3^{\mathrm{d}}$ & $13.5 \pm 1.5^{\mathrm{cd}}$ & $5.0 \pm 0.3^{\mathrm{b}}$ \\
\hline
\end{tabular}




\subsubsection{Effect of X3 particles on radicle elongation of A. lappacea and A. scabra in mine substrates}

X3 significantly enhanced radicle elongation of both species in contaminated waste rock and tailings (Figure 2 and Table 6). In general, radicle elongation of $A$. lappacea was greater under water limited conditions but the opposite was true for tailings. In A. scabra, the longest radicles were observed in amended waste rock at field capacity and in amended tailings under water limited conditions. Under the restricted water regime, radicle length of $A$. lappacea was up to 19 and $13.5 \mathrm{~mm}$ in amended waste rock and tailings respectively as compared with 2 and $3 \mathrm{~mm}$ in unamended treatments. In A. scabra, radicle length was up to 5.5 and $4.5 \mathrm{~mm}$ in amended waste rock and tailings respectively versus 0 and $1 \mathrm{~mm}$ in unamended treatments. At field capacity, radicle length of $A$. lappacea reached 5 and $17.5 \mathrm{~mm}$ in amended waste rock and tailings respectively compared to 0.5 and $0.0 \mathrm{~mm}$ in unamended treatments. Radicle length of $A$. scabra reached 7 and $3.5 \mathrm{~mm}$ in waste rock and tailings respectively as compared to 0.0 and $1.0 \mathrm{~mm}$ in unamended treatments.
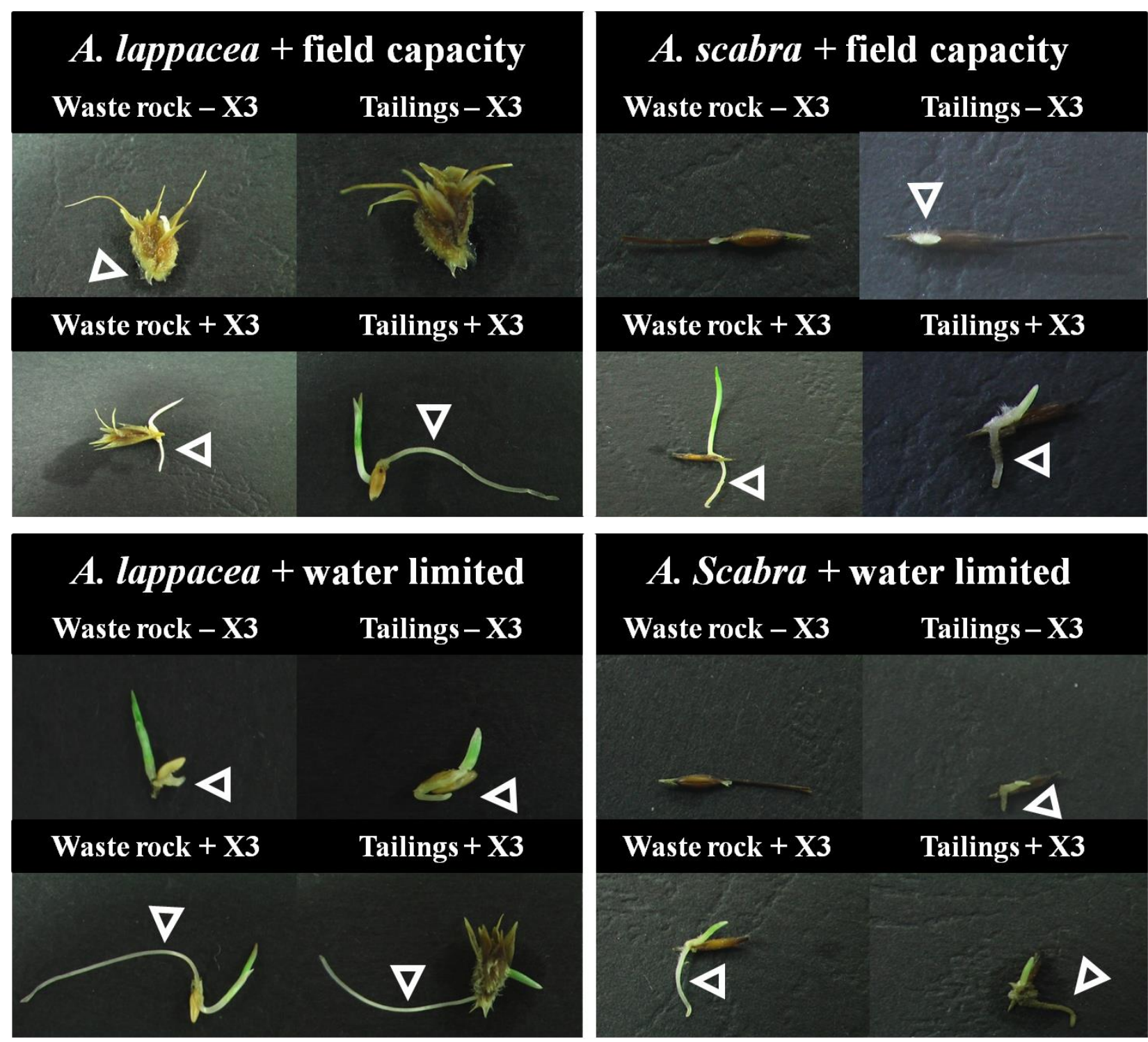

Figure 2 Radicle elongation of $A$. lappacea after four days and $\boldsymbol{A}$. scabra after three days at field capacity and in water limited regime on unamended and $X 3$ amended waste rock (18.4\% DW) and tailings (3.2\% DW). Arrows indicate emergent radicle 
Radicle tolerance index (RTI) of $A$. lappacea and A. scabra was also greatly increased by the addition of X3 in both waste rock and tailings (Table 6). In the presence of X3, the highest RTI of $A$. lappacea was recorded in tailings at field capacity $(138 \%)$ which was significantly $(P<0.05)$ higher than the sand control $(100 \%)$, followed by waste rock under water limited regime $(108 \%)$ which was similar $(P>0.05)$ to the sand control $(100 \%)$. Although the RTIs of the species in X3 amended waste rock at field capacity (almost $53 \%$ ) and tailings under water limited condition (46\%) were lower than in control sand (100\%), they were significantly $(P<0.05)$ higher than in unamended waste rock $(1.1 \%)$ and tailings $(13.6 \%)$ under the same water regime. Regardless of water supply treatment, the RTI of $A$. scabra in waste rock and tailings in the presence of X3 was not significantly different $(P>0.05)$ from the sand control. Large standard errors in some of the treatments were due to variable radicle extension.

Table 6 RTI of $A$. lappacea and $A$. scabra in unamended and X3 amended waste rock $(18.4 \% \mathrm{DW})$ and tailings $(3.2 \% \mathrm{DW}$ of $X 3)$. Results are given as the mean $\pm \mathrm{SE}$ $(n=5)$. Treatments followed by the same letter do not differ significantly $(P>0.05)$; asterisks indicate values based on one replicate only

\begin{tabular}{|c|c|c|c|c|}
\hline \multirow[b]{3}{*}{ Treatment } & \multicolumn{4}{|c|}{ RTI (\%) } \\
\hline & \multicolumn{2}{|c|}{ A. Lappacea } & \multicolumn{2}{|c|}{ A. Scabra } \\
\hline & $\begin{array}{c}\text { Control = } \\
\text { Sand }\end{array}$ & $\begin{array}{l}\text { Control = } \\
\text { Sand + X3 }\end{array}$ & $\begin{array}{c}\text { Control = } \\
\text { Sand }\end{array}$ & $\begin{array}{l}\text { Control = } \\
\text { Sand + X3 }\end{array}$ \\
\hline \multicolumn{5}{|c|}{ a) Waste rock, water limited } \\
\hline Sand & $100 \pm 0.0^{\mathrm{a}}$ & - & $100 \pm 0.0^{\mathrm{a}}$ & - \\
\hline Sand $+X 3$ & $222 \pm 80.3^{a}$ & $100 \pm 0.0^{\mathrm{a}}$ & $67.7 \pm 27.3^{\mathrm{a}}$ & $100 \pm 0.0^{\mathrm{a}}$ \\
\hline Waste rock & $32.3 \pm 22.9^{b}$ & - & $0 \pm 0^{\mathrm{b}}$ & - \\
\hline Waste rock $+\mathrm{X} 3$ & - & $108 \pm 29.5^{\mathrm{a}}$ & - & $65.5 \pm 40.6^{a}$ \\
\hline \multicolumn{5}{|c|}{ b) Waste rock, field capacity } \\
\hline Sand & $100 \pm 0.0^{\mathrm{a}}$ & - & $100 \pm 0.0^{\mathrm{a}}$ & - \\
\hline Sand $+X 3$ & $33 \pm 21^{\mathrm{a}}$ & $100 \pm 0.0^{\mathrm{a}}$ & $34.8 \pm 22.3^{b}$ & $100 \pm 0.0^{\mathrm{a}}$ \\
\hline Waste rock & $1.1 \pm 1.1^{\mathrm{b} *}$ & - & $0 \pm 0^{\mathrm{b}}$ & - \\
\hline Waste rock $+X 3$ & - & $52.8 \pm 2.8^{b}$ & - & $85 \pm 50.6^{a}$ \\
\hline \multicolumn{5}{|c|}{ c) Tailings, water limited } \\
\hline Sand & $100 \pm 0.0^{\mathrm{a}}$ & - & $100 \pm 0.0^{\mathrm{a}}$ & - \\
\hline Sand $+X 3$ & $324 \pm 124.7^{a}$ & $100 \pm 0.0^{\mathrm{a}}$ & $150 \pm 38^{a}$ & $100 \pm 0.0^{\mathrm{a}}$ \\
\hline Tailings & $13.6 \pm 13.6^{\mathrm{b} *}$ & - & $24.7 \pm 10.4^{b}$ & - \\
\hline Tailings $+X 3$ & - & $46.1 \pm 18.7^{b}$ & - & $74.5 \pm 24.8^{\mathrm{a}}$ \\
\hline \multicolumn{5}{|c|}{ d) Tailings, field capacity } \\
\hline Sand & $100 \pm 0.0^{\mathrm{a}}$ & & $100 \pm 0.0^{a}$ & \\
\hline Sand $+X 3$ & $34.2 \pm 19.7^{b}$ & $100 \pm 0.0^{a}$ & $129 \pm 29.3^{a}$ & $100 \pm 0.0^{a}$ \\
\hline Tailings & $0 \pm 0^{c}$ & & $6.7 \pm 6.7^{b}$ & \\
\hline Tailings $+X 3$ & - & $138 \pm 73.2^{b}$ & - & $103 \pm 22.5^{a}$ \\
\hline
\end{tabular}

\section{$5 \quad$ Discussion}

This study was the first to assess the capacity of micron-sized thiol functional cross-linked acrylamide polymer hydrogel particles (X3) to bind metals in contaminated waste rock and tailings, and to increase water holding capacities of the substrates. It demonstrated that addition of novel X3 particles led to improved seed germination in both phytotoxic mine substrates. 
In this study, the plant available concentrations of $\mathrm{Al}$ and $\mathrm{Cu}$ in mine waste rock were significantly reduced by the addition of $\mathrm{X} 3$ to below the phytotoxicity thresholds for both native metallophyte grasses A. lappacea and A. scabra, thereby allowing the seeds to germinate. This has previously been shown to be due to the irreversible adsorption of these metals by the thiol functional group of X3 (Rossato et al., 2011). The increase of $\mathrm{pH}$ in the waste rock amended with $\mathrm{X} 3$ might also have contributed to the reduction of metal availability to seeds as $\mathrm{Al}$ and $\mathrm{Cu}$ are more available in low pH (Adriano, 2001; Kikui et al., 2005; Meda and Furlani, 2005). Falatah et al. (1996) also reported increased pH of soil with the addition of 0.2 to $0.6 \%(\mathrm{w} / \mathrm{w}$ ) of polymers (Broadleaf P4, Agrihobe, Aquasorb and hydrogel). Other studies have investigated the use of micron-size polymers for mine soil remediation. For example, Qu and de Varennes (2010) reported a considerable decrease of water-extractable $\mathrm{Pb}, \mathrm{Cu}$ and $\mathrm{Zn}$ in mine soils following application of cross-linked polyacrylate hydrogel polymer. However, in $\mathrm{Pb}$ contaminated soil, the metal-binding capacity of the polymer was found to compete with its water holding capacity which decreased progressively as the polymer sorbed $\mathrm{Pb}$ (Guiwei et al., 2008). Activities of soil enzymes such as urease were also impaired by the addition of the polymer, which suggested alteration of soil microbial functionality (Guiwei et al., 2008). Addition of polymer also promoted the formation of microsites rich in water and nutrient, which were favourable to roots and microorganisms ( $Q u$ and de Varennes, 2010).

$\mathrm{X} 3$ remarkably increased water holding capacities of both waste rock and tailings. This increase is crucial as it could provide water to plants in drought conditions by slowly releasing water to the roots (Rossato et al., 2009) and enhancing plant establishment particularly in metal contaminated sites (Mendez and Maier, 2008). Previous studies demonstrated that the water absorbing capacity and the degree of swelling in hydrogels decreased with increasing salinity (Hussien et al., 2012; Qu and de Varennes, 2010). Our study shows that the effectiveness of $X 3$ particles in increasing WHCs of the extremely saline waste rock and tailings was not affected by the presence of salt. Abd El-Rahim et al. (2006) studied the absorbency of superabsorbent hydrogel (polyacrylamide/potassium polyacrylate) in different salt solutions and showed that the absorbent capacity of the hydrogel decreased rapidly at lower $\mathrm{pH}(4-2)$. In the current study, $\mathrm{pH}$ did not have any effect on the capacity of $\mathrm{X} 3$ to increase the water holding capacities of waste rock and tailings at or above $\mathrm{pH} 3.2$.

Our study shows that with the addition of X3 particles, seeds of A. lappacea and A. scabra were able to germinate on extremely saline and metal contaminated waste rock and tailings which were previously phytotoxic. Seed germination and root elongation have been used in the past to evaluate toxicity of nanoparticles on higher plants (Ma et al., 2011) as this is the first physiological stage of plant growth affected by metals (Shanker et al., 2005). In contrast with other nanoparticles which had toxic effects on seed germination, such as zero-valent iron and nanosilvers on shoot growth of ryegrass, barley and flax (ElTemsah and Joner, 2012), nano-scale $\mathrm{Fe}_{3} \mathrm{O}_{4}, \mathrm{TiO}_{2}$ and carbon particles on root growth of cucumber (Mushtaq, 2011) and nanomaterial quantum dots on germination of rice seeds (Nair et al., 2011), our study confirms that the $\mathrm{X} 3$ particles are not toxic to seed germination and supports the previous findings by Rossato et al. (2011). Addition of X3 to waste rock and tailings significantly increased germination percentages, root length and RTI of both grass species which suggests alleviation of toxicity in amended substrates (Torres and de Varennes, 1998). Enhanced germination of the seeds and radicle elongation in the presence of $X 3$ hydrogel polymer particles under water restricted conditions confirm the ability of $X 3$ to store and progressively release water to plant roots and to improve plant water relations under drought conditions. This is consistent with other studies on hydrogels which have been reported to stimulate root proliferation and aggregation, leading to increased contact with moisture and improved water use efficiency (Agaba et al., 2011) which in turn increased shoot and root biomass (Davies and Castro-Jimenez, 1989; Dorraji et al., 2010). Addition of acrylamide based hydrogels to sandy soils for cultivation purposes was also found to improve water retention of the soil matrix, reduce plant watering frequency and increase plant growth and performance (Abd El-Rehim et al., 2004). Additional benefits of amending soils with acrylamide based polymers include increased (Blodgett et al., 1993) and prolonged (Huttermann et al., 1999) plant water availability when irrigation ceased, reduction of soil erosion, water runoff and compaction, and increased aeration, microbial activity and plant survival (Abd El-Rehim et al., 2004; Guiwei et al., 2008). 


\section{Conclusion}

Our study shows that X3 micron-size particles significantly ameliorated the quality of mine waste substrates in such a way as to alleviate metal toxicity to radicles, and provide moisture in water restricted conditions. This led to improved imbibition and the subsequent germination and radicle elongation of $A$. lappacea and $A$. scabra seeds in otherwise phytotoxic mine waste rock and tailings. Further research will investigate the interactions between the $\mathrm{X} 3$ polymer, water and ions in a long-term glasshouse experiment on contaminated mine wastes and their effects on plant establishment in phytotoxic conditions. Sustainability of the $\mathrm{X} 3$ particles in mine spoils will also be tested.

\section{Acknowledgements}

The study was funded by a Pathfinder grant from UniQuest Pty Ltd (The University of Queensland, Australia). The authors are grateful to $\mathrm{Mr}$ Craig Claremont, summer scholarship student recipient at the University of Queensland, for his assistance with the experimental work. The assistance from mine site personnel and comments of the anonymous reviewers are gratefully acknowledged.

\section{References}

Abd El-Rehim, H.A., Hegazy, E.A. and Abd El-Mohdy, H.L. (2004) Radiation synthesis of hydrogels to enhance sandy soils water retention and increase plant performance, Journal of Apply Polymer Science, Vol. 93, pp. 1360-1371.

Abd El-Rehim, H.A., Hegazy, E.A. and Abd El-Mohdy, H.L. (2006) Effect of Various Environmental Conditions on the Swelling Property of PAAm/PAAcK Superabsorbent Hydrogel Prepared by lonizing Radiation, Journal of Applied Polymer Science, Vol. 101, pp. 3955-3962.

Adriano, D.C. (2001) Trace elements in terrestrial environments: biogeochemistry, bioavailability, and risks of metals, USA: Springer, $867 \mathrm{p}$.

Agaba, H., Orikiriza, L.J.B., Obua, J., Kabasa, J.D., Worbes, M. and Huttermann, A. (2011) Hydrogel amendment to sandy soil reduces irrigation frequency and improves the biomass Agrostis stolonifera, Agricultural Sciences, Vol. 2, pp. 544-550.

Alvarez, E., Fernandez Marcos, M.L., Vaamonde, C. and Fernandez-Sanjurjo, M.J. (2003) Heavy metals in the dump of an abandoned mine in Galicia (NW Spain) and in the spontaneously occurring vegetation, Science of the Total Environment, Vol. 313, pp. 185-197.

Antonijevic, M.M., Dimitrijevic, M.D., Milic, S.M. and Nujkic, M.M. (2012) Metal concentrations in the soils and native plants surrounding the old flotation tailings pond of the Copper Mining and Smelting Complex Bor (Serbia), Journal of Environmental Monitoring, Vol. 14, pp. 866-877.

Bell, C.A., Smith, S.V., Whittaker, M.R., Whittaker, A.K., Gahan, L.R. and Monteiro, M.J. (2006) Surface-functionalized polymer nanoparticles for selective sequestering of heavy metals, Advanced Materials, Vol. 18, pp. 582-586.

Belsky, A.J., Amundson, R.G., Duxbury, J.M., Riha, S.J., Ali, A.R. and Mwonga, S.M. (1989) The effects of trees on their physical, chemical and biological environments in a semi-arid savanna in Kenya, The Journal of Applied Ecology, Vol. 26, pp. 1005-1024.

Blodgett, A.M., Beattie, D.J., White, J.W. and Elliott, G.C. (1993) Hydrophilic polymers and wetting agents affect absorption and evaporative water loss, HortScience, Vol. 28, pp. 633-635.

Davies, F.T. Jr. and Castro-Jimenez, Y. (1989) Water relations of Lagerstroemia indica grown in amended media under drought stress, Scientia Horticulturae, Vol. 41, pp. 97-104.

de Varennes, A. and Queda, C. (2005) Application of an insoluble polyacrylate polymer to copper-contaminated soil enhances plant growth and soil quality, Soil Use and Management, Vol. 21, pp. 410-414.

de Varennes, A., Qu, G., Cordovil, C. and Goncalves, P. (2011) Soil quality indicators response to application of hydrophilic polymers to a soil from a sulfide mine, Journal of Hazardous Materials, Vol. 192, pp. 1836-1841.

Dorraji, S.S., Golchin, A. and Ahmadi, S. (2010) The Effects of Hydrophilic Polymer and Soil Salinity on Corn Growth in Sandy and Loamy Soils, Clean-Soil Air Water, Vol. 38, pp. 584-591.

Ellis, R.H. and Roberts, E.H. (1981) The qualification of ageing and survival in orthodox seeds, Seed Science and Technology, Vol. 9, pp. 373-409.

El-Temsah, Y.S. and Joner, E.J. (2012) Impact of Fe and Ag nanoparticles on seed germination and differences in bioavailability during exposure in aqueous suspension and soil, Environmental Toxicology, Vol. 27, pp. 42-49.

Falatah, A.M., Choudhary, M.I. and Al-Omran, A.M. (1996) Changes in some chemical properties of arid soils as affected by synthetic polymers, Arid Soil Research and Rehabilitation, Vol. 10, pp. 277-285.

Guiwei, Q., de Varennes, A. and Cunha-Queda, C. (2008) Remediation of a mine soil with insoluble polyacrylate polymers enhances soil quality and plant growth, Soil Use and Management, Vol. 24, pp. 350-356.

Hegazy, A.K., Abdel-Ghani, N.T. and El-Chaghaby, G.A. (2011) Phytoremediation of industrial wastewater potentiality by Typha domingensis, International Journal of Environmental Science and Technology, Vol. 8, pp. 639-648. 
Hussien, R.A., Donia, A.M., Atia, A.A., El-Sedfy, O.F., Abd El-Hamid, A.R. and Rashad, R.T. (2012) Studying some hydro-physical properties of two soils amended with kaolinite-modified cross-linked poly-acrylamides, Catena, Vol. 92, pp. $172-178$.

Huttermann, A., Zommorodi, M. and Reisa, K. (1999) Addition of hydrogels to soil for prolonging the survival of Pinus halepensis seedlings subjected to drought, Soil and Tillage Research, Vol. 50, pp. 295-304.

Keeling, S.M. and Werren, G. (2005) Phytoremediation: The uptake of metals and metalloids by Rhodes grass grown on metalcontaminated soil, Remediation Journal, Vol. 15, pp. 53-61.

Kikui, S., Sasaki, T., Maekawa, M., Miyao, A., Hirochika, H., Matsumoto, H. and Yamamoto, Y. (2005) Physiological and genetic analyses of aluminium tolerance in rice, focusing on root growth during germination, Journal of Inorganic Biochemistry, Vol. 99, pp. 1837-1844.

Kopittke, P.M., Blamey, F.P.C., Asher, C.J. and Menzies, N.W. (2010) Trace metal phytotoxicity in solution culture: a review, Journal of Experimental Botany, Vol. 61, pp. 945-954.

Ma, Y.H., He, X., Zhang, P., Zhang, Z.Y., Guo, Z., Tai, R.Z., Xu, Z.J., Zhang, L.J., Ding, Y.Y., Zhao, Y.L. and Chai, Z.F. (2011) Phytotoxicity and biotransformation of La2O3 nanoparticles in a terrestrial plant cucumber (Cucumis sativus), Nanotoxicology, Vol. 5, pp. 743-753.

Meda, A.R. and Furlani, P.R. (2005) Tolerance to aluminium toxicity by tropical leguminous plants used as cover crops, Brazilian Archives of Biology and Technology, Vol. 48, pp. 309-317.

Mendez, M.O. and Maier, R.M. (2008) Phytostabilization of mine tailings in arid and semiarid environments - an emerging remediation technology, Environmental Health Perspectives, Vol. 116, pp. 278-283.

Menzies, N.W., Donn, M.J. and Kopittke, P.M. (2007) Evaluation of extractants for estimation of phytoavailable trace metals in soils, Environmental Pollution, Vol. 145, pp. 121-130.

Mulvey, P.J. and Elliott, G.L. (2000) Toxicities in soils, Soils: their properties and management, 2nd edition, P.E.V. Charman and B.W. Murphy (eds), Oxford University Press, South Melbourne, Australia, p. 254.

Mushtaq, Y.K. (2011) Effect of nanoscale Fe3O4, TiO2 and carbon particles on cucumber seed germination, Journal of Environmental Science and Health, Part A, Vol. 46, pp. 1732-1735.

Nair, R., Poulose, A.C., Nagaoka, Y., Yoshida, Y., Maekawa, T. and Kumar, D.S. (2011) Uptake of FITC labeled silica nanoparticles and quantum dots by rice seedlings: Effects on seed germination and their potential as biolabels for plants, Journal of Fluorescence, Vol. 21, pp. 2057-2068.

Nedunuri, K.V., Lowell, C., Meade, W., Vonderheide, A.P. and Shann, J.R. (2010) Management Practices and Phytoremediation by Native Grasses, International Journal of Phytoremediation, Vol. 12, pp. 200-214.

Qu, G. and de Varennes, A. (2010) Use of hydrophilic polymers from diapers to aid the establishment of Spergularia purpurea in a mine soil, Journal of Hazardous Materials, Vol. 178, pp. 956-962.

Rayment, G.E. and Higginson, F.R. (1992) Australian laboratory handbook of soil and water chemical methods, Melbourne/Sydney, Inkata Press.

Rossato, L., MacFarlane, J., Whittaker, M., Pudmenzky, A., Doley, D., Schmidt, S. and Monteiro, M.J. (2011) Metal-binding particles alleviate lead and zinc toxicity during seed germination of metallophyte grass Astrebla lappacea, Journal of Hazardous Materials, Vol. 190, pp. 772-779.

Rossato, L., Pudmenzky, A., Doley, D., Monteiro, M.J., Whittaker, M.R., Schmidt, S., MacFarlane, J. and Baker, A.J.M. (2009) Metalbinding particles enhance germination and radicle tolerance index of the metallophyte grass Astrebla lappacea under phytotoxic lead and zinc conditions, in Proceedings Fourth International Conference on Mine Closure (Mine Closure 2009), A.B. Fourie and M. Tibbett (eds), 9-11 September 2009, Perth, Australia, Australian Centre for Geomechanics, Perth, pp. 302-310.

Salt, D.E., Blaylock, M., Kumar, N.P.B.A., Dushenkov, V., Ensley, B.D., Chet, I. and Raskin, I. (1995) Phytoremediation: a novel strategy for the removal of toxic metals from the environment using plants, Biotechnology, Vol. 13, pp. 468-474.

Shanker, A.K., Cervantes, C., Loza-Tavera, H. and Avudainayagam, S. (2005) Chromium toxicity in plants, Environment International, Vol. 31, pp. 739-753.

Singh, R., Misra, V. and Singh, R.P. (2012) Removal of Cr(VI) by Nanoscale Zero-valent Iron (nZVI) from Soil Contaminated with Tannery Wastes, Bulletin of Environmental Contamination and Toxicology, Vol. 88, pp. 210-214.

Sun, Y.P., Li, X., Cao, J., Zhang, W. and Wang, H.P. (2006) Characterization of zero-valent iron nanoparticles, Advances in Colloid and Interface Science, Vol. 120, pp. 47-56.

The State of Queensland (2011) Salinity Management Handbook, 2nd edition, Department of Environment and Resource Management, Brisbane, Australia.

Tiedemann, A.R. and Klemmedson, J.O. (2004) Responses of desert grassland vegetation to mesquite removal and regrowth, Journal of Range Management, Vol. 57, pp. 455-465.

Torres, M.O. and de Varennes, A. (1998) Remediation of a sandy soil artificially contaminated with copper using a polyacrylate polymer, Soil Use and Management, Vol. 14, pp. 106-110.

USEPA (2005) United States Environmental Protection Agency. Nanotechnology for site remediation, in US EPA Workshop on nanotechnology for site remediation, October 20-21, 2005, US Department of Commerce, Washington DC.

Williams, D.J. and Currey, N.A. (2002) Engineering closure of an open pit gold operation in a semi-arid climate, International Journal of Surface Mining, Reclamation and Environment, Vol. 16, pp. 270-288. 
Micron-size metal-binding hydrogel particles improve germination and radicle

J. Guterres et al. elongation of Australian metallophyte grasses in mine waste rock and tailings 